\title{
Immunoreactive material resembling vertebrate neuropeptides in the corpus cardiacum and corpus allatum of the insect Leucophaea maderae*
}

\author{
Bente Langvad Hansen, Georg Nørgaard Hansen, and Berta Scharrer \\ Institute of Medical Microbiology and Institute of Comparative Anatomy, University of Copenhagen, \\ Denmark, and Departments of Anatomy and Neuroscience, Albert Einstein College of Medicine, New \\ York, USA
}

\begin{abstract}
Summary. The presence and differential distribution of substances antigenically related to known vertebrate neuropeptides demonstrated within the corpus cardiacum of the insect Leucophaea are as follows: Of ten mammalian antisera tested, six yielded substantial immunoreactive deposits resembling oxytocin, somatostatin, Substance $P$, met-enkephalin, bombesin, and neurotensin, respectively. In the remaining four, the reaction was moderate (vasopressin, $\beta$ endorphin) or marginal (LH-RF, calcitonin). With regard to their regional distribution, these biochemically distinct reaction products seem to fall into two groups: (1) Materials resembling oxytocin, vasopressin, met-enkephalin, $\beta$ endorphin (and presumably also neurotensin and LH-RF) predominate in the central release area of the organ and are considered to be of extrinsic (cerebral) origin. (2) Substances localized primarily in areas rich in intrinsic glandular cells of the corpus cardiacum, and revealed by antisera raised against somatostatin, Substance $P$, and bombesin, are judged to be synthesized and stored within this organ. In peptidergic fibers entering the adjacent corpora allata, thus far Substance P-, $\beta$-endorphin-, and LH-RF-like immunoreactivities have been demonstrated. Some of these "new" neuropeptides may be contained in classical neurosecretory neurons, formerly identified by less specific methods, others must be assigned to additional peptidergic neurons heretofore unknown.
\end{abstract}

Key words: Vertebrate-type neuropeptides -Neuroendocrine system of insects Neurosecretion - Peptidergic neurons - Immunocytochemistry

The rapidly growing body of information on the wide distribution and diverse roles of neuropeptides has evoked considerable interest in their evolutionary history. The search for such active principles, above and beyond those furnished by classical

Send offprint requests to: Dr. Bente L. Hansen, Institute of Medical Microbiology, University of Cópenhagen, 22 Juliane Maries Vej, DK-2100 Copenhagen $\varnothing$, Denmark, or Dr. Berta Scharrer, Department of Anatomy, Albert Einstein College of Medicine, 1300 Morris Park Avenue, Bronx, New York 10461, USA

* Supported by NSF grant BMS 74-12456 (B.S.). The excellent technical assistance of Mrs. Sarah Wurzelmann is gratefully acknowledged 
neurosecretory neurons, has yielded positive results in all major phyla of invertebrates including the coelenterates (see Haynes 1980). In insects, with their rather complex neuroendocrine control mechanisms, the operation of a variety of neuropeptides would seem to be as plausible as in vertebrates. Much of the current information on the localization of certain "mammalian" as well as "invertebrate" neuropeptides in this group of arthropods has been obtained by immunocytochemical tests (e.g., Rémy and Dubois 1981). Additional evidence has resulted from radioimmunoassay (e.g., Gros et al. 1978; Proux et al. 1980) and receptor binding studies (Stefano and Scharrer 1981). Most of these data refer to the demonstration of such neuroactive substances in the central nervous system of various insect species, only a few to those found in the corpora cardiaca, i.e., neurohemal organs for peptides of cerebral as well as intrinsic origin. The present study deals with the immunocytochemical demonstration of reaction products of several antisera to mammalian neuropeptides in the corpus cardiacum-allatum of the blattarian insect Leucophaea maderae.

\section{Materials and methods}

The corpora cardiaca, together with the adjacent corpora allata, of adult males and females of Leucophaea were fixed in situ in Bouin's solution. Sections of the paraffin-embedded tissues, cut at $6 \mu \mathrm{m}$, were used for immunocytochemical tests according to the unlabelled-antibody enzyme method of Sternberger (1979). The procedural details were as previously described (Hansen et al. 1980; Hansen and Hansen 1982). Antisera obtained from INC (Immuno Nuclear Corporation, Stillwater, Minnesota) were all raised in rabbits against synthetic products. These sera have been evaluated by the manufacturer to contain specificity against the ligands and are claimed to react with cells in the rat brain and pituitary known to contain the peptides in question.

Immunological specificity (first level controls) of the primary antisera was judged by the criterium of differences in the distribution and morphology of the positively "stained" structures. In the present material, no other controls are entirely valid (see Discussion). Method specificity (second level controls) was determined as follows: (1) application of nonimmune rabbit IgG and serum instead of primary specific antiserum; (2) comparative use of sera with different specificities (these contribute to the method controls as the recommended use of known hyperimmune immunoglobulin replacing the primary antiserum); (3) successive omission of secondary layers. Sensitivity of immunostaining was tested by progressive dilutions of the primary antisera used from $1: 100$ to $1: 2,000$.

The list of antisera tested (Table 1) includes two raised against the neurohypophysial hormones vasopressin and oxytocin, two against the hypophysiotropins somatostatin and LH-RF (luteinizinghormone releasing factor), two against the endogenous opioids $\beta$-endorphin and met-enkephalin, and four raised against Substance $P$, neurotensin, bombesin, and calcitonin, respectively.

\section{Results}

Method specificity. No staining was obtained after control treatments (1) and (3) as specified in Materials and methods.

Immunological specificity. Use of the different hyperimmune sera resulted in staining of differentially distributed material in the serially sectioned corpus cardiacum. This result simultaneously supports the method specificity (see item 2 under Materials and methods) and the specificity of the primary antibodies to be directed against different antigens. 
Table 1. Antisera raised against mammalian neuropeptides yielding reaction products in the corpora cardiaca of Leucophaea

\begin{tabular}{ll}
\hline Type of peptide & Degree of reaction \\
\hline Oxytocin & +++ \\
Somatostatin & +++ \\
Substance $\mathbf{P}$ & +++ \\
Met-enkephalin & +++ \\
Bombesin & +++ \\
Neurotensin & $+++1++$ \\
Vasopressin & ++ \\
$\beta$-endorphin & ++ \\
LH-RF & $(+)$ \\
Calcitonin & $(+)$ \\
\hline
\end{tabular}

Sensitivity of immunostaining. Progressive dilution of the primary antisera gradually decreases staining. At dilutions of anti-oxytocin $1: 1,000$, antivasopressin 1:800, anti-somatostatin 1:1,500, anti-LH-RF 1:1,000, anti- $\beta$ endorphin 1:400, anti-met-enkephalin $1: 2,000$, anti-Substance $P 1: 500$, antineurotensin $1: 1,000$, anti-bombesin $1: 800$, and anti-calcitonin $1: 800$ staining was no longer observable. Optimal staining for each of the antisera tested was observed at dilutions from $1: 100$ to $1: 400$.

The result of this study was the demonstration of the presence and differential distribution of several substances antigenically related to known vertebrate neuropeptides in the corpus cardiacum, a component of the neuroendocrine system of the insect Leucophaea. Six of the ten mammalian antisera tested yielded substantial immunoreactive deposits in distinctive areas of the corpora cardiaca. In two others the reaction was moderate, and in two marginal (Table 1).

The fact that the distribution of these reaction products is regional rather than diffuse is meaningful in that it reflects the topography characteristic of the corpora cardiaca of Leucophaea (Scharrer 1963). This paired elongated structure which lines the dorsal blood vessel is a composite organ known to contain several peptides with distinctive neurohormonal properties of intrinsic as well as extrinsic origin. Their cells of origin have been identified by means of selective staining methods, e.g., aldehyde fuchsin, and by electron microscopy. The central (neural) zone of the organ consists primarily of nerve fibers, the peripheral (lateral) layer is rich in intrinsic neuroglandular cells. The latter are more diffusely arranged in the caudal area where the corpora cardiaca are contiguous with the corpora allata.

Extrinsic peptides, manufactured by classical neurosecretory neurons located in the protocerebrum, are transported to their neurohemal storage site in the corpus cardiacum via the nervi corporis cardiaci. These axon bundles running in anteroposterior direction occupy the more medial area of the organ. Their terminals, lined up along the lumen of the dorsal vessel, afford the secretory product ready access to the circulation. Other peptides, furnished by the intrinsic neuroglandular cells, also are stored in cellular processes extending to the ventral and lateral as well as medial surfaces of the corpus cardiacum. These too can reach the circulation, either by release into the dorsal blood vessel or into the hemocoel surrounding the entire 

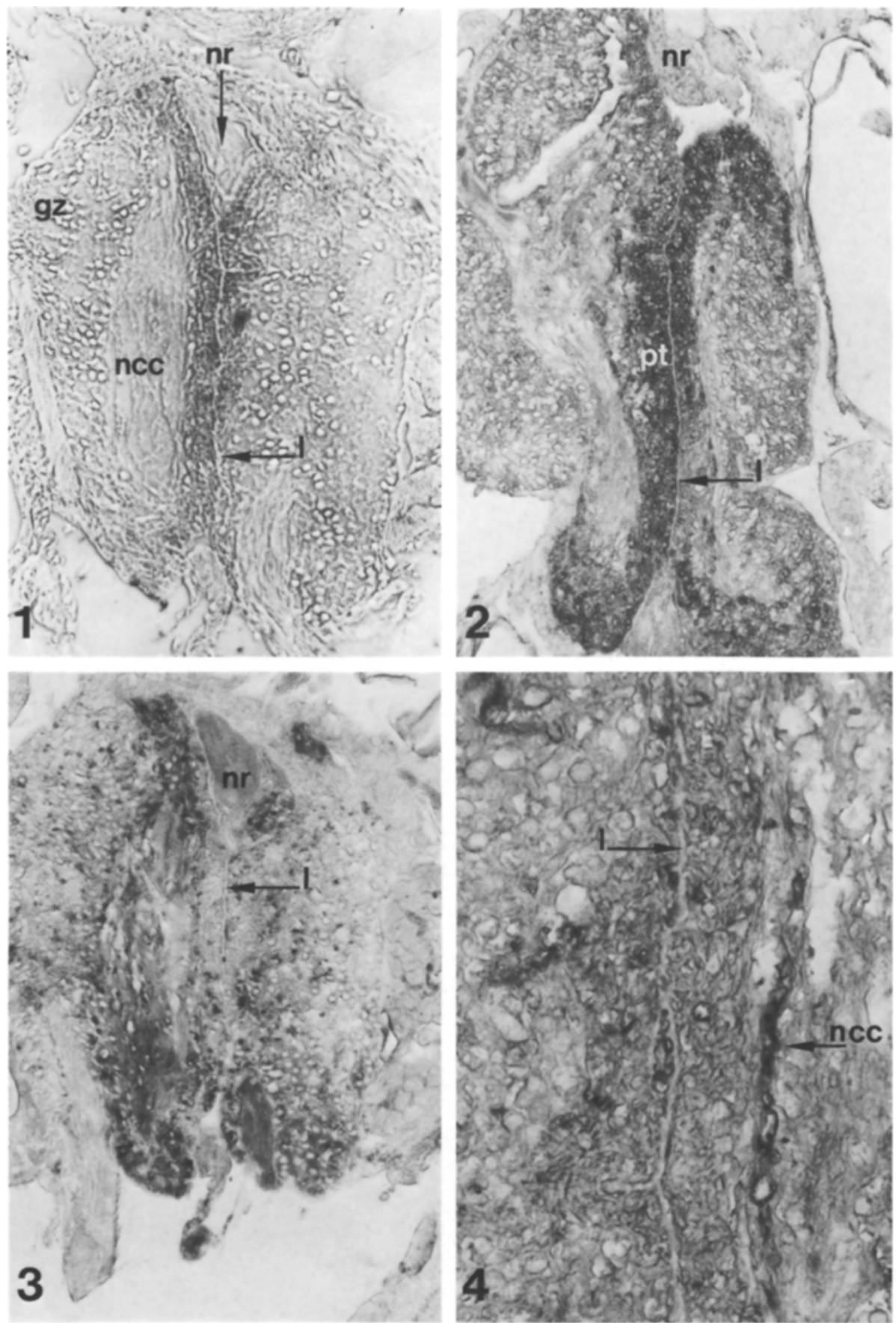

Figs. 1-4. Longitudinal sections through corpora cardiaca of Leucophaea showing reaction products of vasopressin (Fig. 1), oxytocin (Fig. 2), IgG control (Fig. 3), neurotensin (Fig. 4). l lumen of dorsal blood vessel in center; $p t$ peptidergic terminals; ncc nervus corporis cardiaci; $g z$ glandular (intrinsic) zone of corpus cardiacum, lateral; $n r$ nervus recurrens. Figs. $1-3, \times 170 ;$ Fig. $4, \times 440$ 



Fig. 5. Longitudinal section through corpus cardiacum and adjacent corpus allatum showing Substance P-like material (arrows), in intrinsic-cell zone of c. cardiacum $(c c)$ and within c. allatum $(c a) . \times 510$

Fig. 6. Strong somatostatin-like immunoreactivity in intrinsic (lateral) zone of c. cardiacum $(c c) . d v$ dorsal vessel; $p t$ peptidergic terminals with some reaction product; $n c c$ nervus corporis cardiaci; $n r$ nervus recurrens. $\times 170$

Fig. 7. Bombesin-like material in intrinsic-cell zone of c. cardiacum $(c c) \times 440$ 

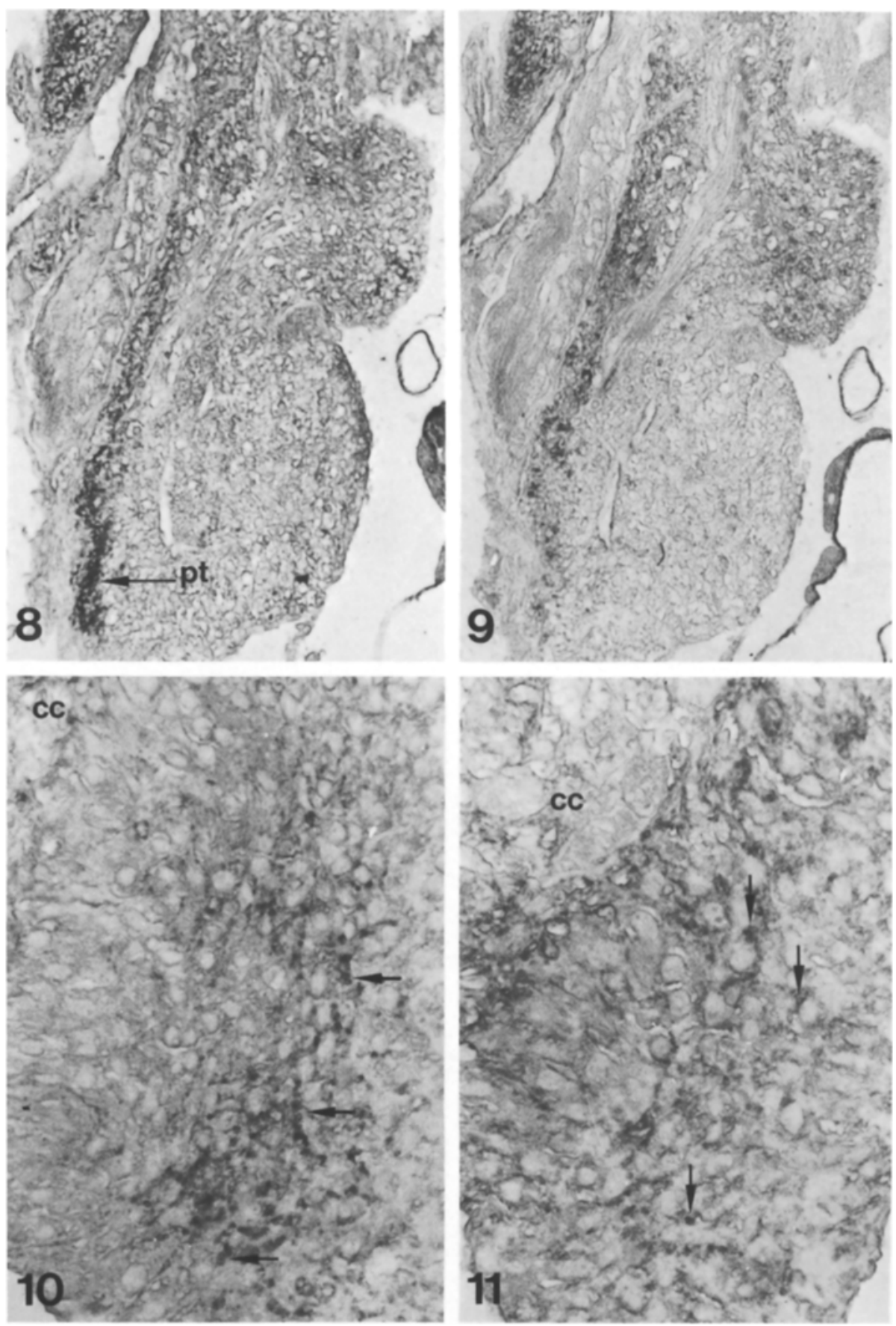

Figs. 8-9. Pair of sections showing met-enkephalin reactivity in central release zone $(p t)$ facing dorsal vessel (Fig. 8) and IgG control (Fig. 9). $\times 170$

Figs. 10-11. Corpus allatum sections showing $\beta$-endorphin-like (Fig. 10) and LH-RF-like material (Fig. 11) (arrows); $c c$ corpus cardiacum. $\times 440$ 
organ. Some peptidergic fibers, presumably of protocerebral origin, make direct contact with intrinsic corpus cardiacum cells, others can be traced to the adjacent corpora allata where they terminate in close proximity to the cells of this endocrine organ.

The immunoreactive deposits demonstrated in the present study, like the previously recognized neuropeptides, seem to fall into two groups according to their predominant localization within the corpus cardiacum. Group one includes the materials resembling oxytocin, vasopressin, met-enkephalin, $\beta$-endorphin, and presumably also neurotensin and LH-RF (Figs. 1, 2, 4, 8). As exemplified by the "oxytocin" pattern (Fig. 2), their reaction products predominate in the central release area facing the dorsal blood vessel, and may be visible also in the path of the nervi corporis cardiaci. They seem to be absent in the cellular area of the organ (compare Figs. 1 and 3). In group two, comprised of the reaction products of somatostatin (Fig. 6), Substance P (Fig. 5) and bombesin (Fig. 7), the localization is primarily in the area of the intrinsic cells and to a smaller extent in that of their processes.

It is reasonable to suggest, therefore, that the immunoreactive material accumulated primarily in and close to the central release zone (group 1) represents "new" neuropeptides of extrinsic origin, stored in the neurohemal part of the organ. By the same token, the reaction products demonstrated in the lateral area of the corpus cardiacum (group 2) indicate that additional substances resembling "vertebrate" neuropeptides may be synthesized in loco, i.e., in the intrinsic neuroglandular cells. Because of the differential distribution of these newly detected neuropeptides, presumed to reflect biochemical distinctiveness, the immunoreactive deposits of group one may serve as controls for those of group two, and vice versa.

Preliminary examination of the corpora allata, known to receive directives from peptidergic neurons entering via the corpora cardiaca, revealed reaction products in sections treated with antisera against Substance $\mathrm{P}, \beta$-endorphin, or LH-RF (Figs. 5 , $10,11)$ in amounts commensurate with the localized nature of their putative role.

\section{Discussion}

A recurring question in immunocytochemical determinations concerns the specificity of the antibodies used and the validity of the results in terms of a precise definition of previously unknown invertebrate neuropeptides. First level controls are of utmost importance in immunocytochemical techniques, and so far absorption controls represent the only way of detecting antibody specificity. However, in a study such as the present, with the use of antibodies prepared against mammalian peptides in the search for reaction products in insects, absorption of the antibodies with known mammalian peptides is of little informative value.

The correct absorption controls for the present purpose, i.e., the characterization of the respective antibodies/antigens would involve the use of extraction products from the insect in question. At present, the chemical nature of such putative insect antigens is largely unknown, and the positive immunoreaction may therefore be considered as in situ absorption, providing additional information about the anatomical distribution of material antigenically cross-reactive with one or another of the mammalian peptides against which the antibodies used are 
directed. This may provide the basic information for future extraction experiments in order to characterize cross-reactive material of insects.

The fact that neuropeptides resembling those of vertebrates occur in neuroendocrine centers of many invertebrates is, however, well established (see Frontali and Gainer 1977; Scharrer 1978; Haynes 1980). In insects, a number of such substances have been demonstrated in the central nervous system, especially the cerebral and subesophageal ganglia, by immunocytochemical procedures. These include peptides resembling vasopressin and neurophysin (e.g., Strambi et al. 1979; Girardie and Rémy 1980; Rémy and Girardie 1980), somatostatin (DoerrSchott et al. 1978), the endogenous opioids enkephalin (Rémy and Dubois 1981) and endorphin (Rémy et al. 1978), and members of the gastroenteropancreatic system (Duve and Thorpe 1979, 1980, 1981; Yui et al. 1980; El-Salhy 1981).

By contrast, only two comparable immunocytochemical tests with antisera to vertebrate peptides have thus far been reported for the corpus cardiacum, suggesting the presence of a somatostatin-like material in Locusta (Doerr-Schott et al. 1978) and of an insulin-like material in Bombyx (Yui et al. 1980). Radioimmunoassays have revealed glucagon- as well as insulin-like peptides in corpus cardiacum-corpus allatum complexes of Manduca (Tager et al. 1976), and enkephalin-like material in the corpus cardiacum and in the central nervous ganglia of Locusta (Gros et al. 1978).

Thus, with the exception of somatostatin and met-enkephalin the immunoreactivities reported in the present study introduce a series of "new" vertebrate-type neuropeptides for the corpus cardiacum. What can be surmised from these data with reasonable assurance is that the variety of neuropeptides present in the corpus cardiacum of Leucophaea, and presumably of other species, is greater than anticipated, and that these substances contain amino-acid sequences shared by a number of known vertebrate peptides. The existence of such commonalities is further documented by the fact that antiserum to a chemically identified molluscan tetrapeptide, FMRF-amide, elicits positive responses in neuroendocrine systems not only of insects, but also of fishes and mammals (Boer et al. 1980).

Another problem to be discussed is the relationship of the neuropeptides detected in the present study to the neurosecretory substances previously identified by means of aldehyde fuchsin staining, and by their ultrastructural characteristics. The concept of the structural and functional complexity of the corpus cardiacumallatum based on these earlier studies has certainly been reinforced by the present data as well as comparable recent reports. However, it is not yet possible to decide which, if any, of the neuroactive principles envisioned by the present experiments may be contained in classical neurosecretory neurons demonstrable by less specific methods in the same "reactive" areas. An argument in favor of such a relationship, aside from the parallelism in localization within the organ, is the knowledge that in insects (as in vertebrates), one and the same neurosecretory neuron may contain more than one neuropeptide. For example, insulin reactivity has been demonstrated in the classical, aldehyde-fuchsin stainable, and gastrin reactivity in the smaller orange-G stainable neurosecretory neurons of the brain of Bombyx (Yui et al. 1980). The same holds for typical neurosecretory A-cells in the subesophageal ganglion of Locusta which strongly react to treatment with anti-vasopressin and anti-neurophysin II (Rémy et al. 1979). On the other hand, a number of the 
immunoreactive structures under consideration must be classified as parts of heretofore unknown peptidergic neurons the recognition of which had to await the development of the more specific cytochemical methods now available. This group is exemplified by four met-enkephalinergic neurons in Locusta that are in close spatial relationship with, but distinct from, the classical neurosecretory neurons of the protocerebrum giving rise to the nervi corporis cardiaci (Rémy and Dubois 1981).

The sites of production of neuropeptides demonstrated in different areas of the corpus cardiacum of Leucophaea cannot be as readily determined as, for example, in Locusta where the topographic separation of the organ into a neural (neurohemal) storage lobe and a glandular lobe is clear-cut. Nevertheless, the suggestion that, for example, the vasopressin-like, and the closely related oxytocinlike peptides present in the central "neural" area of the organ in Leucophaea are derived from the brain seems reasonable since this location corresponds to the pathway of the nervi corporis cardiaci and their terminals whose cells of origin lie in the brain. Moreover, in Locusta a putative neurophysin-like carrier protein of these peptides has been demonstrated not only in the corresponding neurohemal (storage) area but also in neurosecretory cells of the pars intercerebralis of the brain sending their axons to the corpora cardiaca via the tractus nervi corporis cardiaci (Friedel et al. 1980). It is of interest that this arrangement is analogous to that in the hypothalamic-neurohypophysial system. A comparable parallelism between sites of reactivity in the brain as well as the neurohemal component of the corpus cardiacum seems to obtain for the met-enkephalin-like material demonstrated in Locusta (Rémy and Dubois 1981) and in Leucophaea (present study), and also for the somatostatin-like deposits in Locusta (Doerr-Schott et al. 1978).

The characterization of certain immunoreactive peptides observed in the corpus cardiacum of Leucophaea as intrinsic products rests on the fact that they predominate in the laterial and caudal, i.e., cellular areas of the organ. On this basis, the somatostatin-like material in Leucophaea appears to be of intrinsic origin, a conclusion that does not parallel that in Locusta. Genus differences may offer a possible explanation for this discrepancy.

The present additions to the list of neuropeptides previously demonstrated in the corpus cardiacum-allatum raise the question of their functional significance. Their interpretation in terms of the common precursor theory suggests the possibility that some of the substances revealed by their immunoreactivity to antivertebrate antisera may be functionless in the insect. On the other hand, "additional" neuropeptides in insects would not seem to be out of place since modes of peptide-mediated communication other than that by neurohormones are considered to occur in this group as well as in vertebrates.

One of these roles, i.e., neurotransmitter-like mediation, is suggested by the existence of synapse-like structures between peptidergic neurons and various effectors (cells in the corpus cardiacum and the corpus allatum, neurons). Another variant, postulated on the basis of spatial relationships, is neuromodulatory control, e.g., of classical neurosecretory neurons in the neuroendocrine system of locusts by a met-enkephalin-like endogenous opioid (Rémy and Dubois 1981; see also Girardie and Rémy 1980). Finally, the conclusion that met-enkephalin-like neuroregulators operate in insects is strengthened by the recent demonstration of 
high affinity binding sites for a synthetic analog (DALA, D-ala ${ }^{2}$-metenkephalinamide) in the brain of Leucophaea (Stefano and Scharrer 1981). The high density of the putative receptor sites in pregnant adults revealed by these results, and the absence of a sex-related difference in nymphal (i.e., immature) stages may indicate participation of opioid peptides in reproductive physiology. This view is in line with the demonstration, in the present study, of $\beta$-endorphin as well as LH-RF and Substance-P immunoreactivity in nerves entering the corpus allatum, the source of juvenile hormone long known to control egg maturation.

\section{References}

Boer HH, Schot LPC, Veenstra JA, Reichelt D (1980) Immunocytochemical identification of neural elements in the central nervous systems of a snail, some insects, a fish, and a mammal with an antiserum to the molluscan cardio-excitatory tetrapeptide FMRF-amide. Cell Tisue Res 213:21-27

Doerr-Schott J, Joly L, Dubois MP (1978) Sur l'existence dans la pars intercerebralis d'un insecte ( Locusta migratoria $\mathrm{R}$ et $\mathrm{F}$ ) de cellules neurosécrétrices fixant un antisérum antisomatostatine. $\mathrm{CR}$ Acad Sc Paris Sér D 286:93-95

Duve H, Thorpe A (1979) Immunofluorescent localization of insulin-like material in the medial neurosecretory cells of the blowfly, Calliphora vomitoria (Diptera). Cell Tissue Res 200:187-191

Duve H, Thorpe A (1980) Localisation of pancreatic polypeptide (PP)-like immunoreactive material in neurones of the brain of the blowfly, Calliphora erythrocephala (Diptera). Cell Tissue Res 210:101109

Duve H, Thorpe A (1981) Gastrin/cholecystokinin (CCK)-like immunoreactive neurones in the brain of the blowfly, Calliphora erythrocephala (Diptera). Gen Comp Endocrinol 43:381-391

El-Salhy M (1981) Immunohistochemical localization of pancreatic polypeptide (PP) in the brain of the larval instar of the hoverfly, Eristalis aenus (Diptera). Experientia 37:1009-1010

Friedel T, Loughton BG, Andrew RD (1980) A neurosecretory protein from Locusta migratoria. Gen Comp Endocrinol 41:487-498

Frontali N, Gainer H (1977) Peptides in invertebrate nervous systems. In: Gainer H (ed) Peptides in neurobiology. Plenum Press, New York London, pp 259-294

Girardie J, Rémy C (1980) Particularités histo-cytologiques des prolongements distaux des 2 cellules à "vasopressine-neurophysine-like" du Criquet migrateur. J Physiol Paris 76:265-271

Gros C, Lafon-Cazal M, Dray F (1978) Présence de substances immunoréactivement apparentées aux enképhalines chez un Insecte, Locusta migratoria. C R Acad Sc Paris Sér D 287:647-650

Hansen GN, Hansen, BL, Hummer L (1980) The cell types in the adenohypophysis of the SouthAmerican lungfish, Lepidosiren paradoxa, with special reference to immunocytochemical identification of the corticotropin-containing cells. Cell Tissue Res 209:147-160

Hansen BL, Hansen GN (1982) Immunocytochemical demonstration of somatotropin-like and prolactin-like activity in the brain of Calamoichthys calabaricus (Actinopterygii). Cell Tissue Res 222:615-628

Haynes LW (1980) Peptide neuroregulators in invertebrates. Prog in Neurobiol 15:205-245

Proux J, Rougon-Rapuzzi G (1980) Evidence for vasopressin-like molecule in migratory locust. Radioimmunological measurements in different tissues: correlation with various states of hydration. Gen Comp Endocrinol 42:378-383

Rémy C, Dubois MP (1981) Immunohistological evidence of methionine enkephalin-like material in the brain of the migratory locust. Cell Tissue Res 218:271-278

Rémy C, Girardie J (1980) Anatomical organization of two vasopressin-neurophysin-like neurosecretory cells throughout the central nervous system of the migratory locust. Gen Comp Endocrinol $40: 27-35$

Rémy C, Girardie J, Dubois MP (1978) Présence dans le ganglion sous-oesophagien de la Chenille processionnaire du Pin (Thaumetopoea pityocampa Schiff) de cellules révélées en immunofluorescence par un anticorps anti- $\alpha$-endorphine. CR Acad Sc Paris Sér D 286:651-653

Rémy C, Girardie J, Dubois MP (1979) Vertebrate neuropeptide-like substances in the suboesophageal ganglion of two insects: Locusta migratoria $\mathrm{R}$ and $\mathrm{F}$ (Orthoptera) and Bombyx mori L (Lepidoptera). Immunocytological investigation. Gen Comp Endocrinol 37:93-100 
Scharrer B (1963) Neurosecretion. XIII. The ultrastructure of the corpus cardiacum of the insect Leucophaea maderae. Z Zellforsch 60:761-796

Scharrer B (1978) Peptidergic neurons: facts and trends. Gen Comp Endocrinol 34:50-62

Stefano GB, Scharrer B (1981) High affinity binding of an enkephalin analog in the cerebral ganglion of the insect Leucophaea maderae (Blattaria). Brain Res 225:107-114

Sternberger L (1979) Immunocytochemistry. 2nd edit. John Wiley, New York, pp 354

Strambi C, Rougon-Rapuzzi G, Cupo A, Martin N, Strambi A (1979) Mise en évidence immunocytologique d'un composé apparenté à la vasopressine dans le système nerveux du grillon Acheta domesticus. CR Acad Sc Paris Sér D 288:131-133

Tager HS, Markese J, Kramer KJ, Speirs RD, Childs CN (1976) Glucagon-like and insulin-like hormones of the insect neurosecretory system. Biochem $J$ 156:515-520

Yui R, Fujita T, Ito S (1980) Insulin-, gastrin-, pancreatic polypeptide-like immunoreactive neurons in the brain of the silkworm, Bombyx mori. Biomed Res 1:42-46

Accepted February 1, 1982 